\title{
Design and Simulation of TCR-TSC in Electric Arc Furnace for Power Quality Improvement at Steel Making Plant (No-1 Iron and Steel Mill, Pyin Oo Lwin, Myanmar)
}

\author{
Thet Mon Aye, Soe Win Naing \\ Dept. of Electrical Power Engineering, Mandalay Technological University, Mandalay, Myanmar
}

Email address:

thetmon.pp@gmail.com (T. M. Aye), soewinnaing2011@gmail.com (S. W. Naing)

To cite this article:

Thet Mon Aye, Soe Win Naing. Design and Simulation of TCR-TSC in Electric Arc Furnace for Power Quality Improvement at Steel Making Plant (No-1 Iron and Steel Mill, Pyin Oo Lwin, Myanmar). Journal of Electrical and Electronic Engineering.

Vol. 3, No. 3, 2015, pp. 30-35. doi: 10.11648/j.jeee.20150303.12

\begin{abstract}
Electric Arc Furnaces (EAFs) are unbalanced nonlinear and time varying loads, which can cause many problems in the power system quality. As the use of arc furnace loads increases in industry, the important of the power quality problems also increase. So, in order to optimize the usage of electric power in EAFs, it is necessary to minimize the effect of arc furnace loads on power quality in power systems as much as possible. Therefore, in this paper, design and simulation of an electric plant supplying an arc furnace is considered. Then by considering the high changes of reactive power and voltage flicker of nonlinear furnace load, a thyristor controlled reactor compensation with thyristor switched capacitor (TCR-TSC) are designed and simulated. Finally, simulation results verify the accuracy of the load modeling and show the effectiveness of the proposed TCR-TSC model for reactive power compensating of the EAF. The installation site for this proposed system is No (1) Iron and Steel Mill (Pyin- Oo- Lwin). And data is taken from this Steel Mill. Simulation results will be provided by using MATLAB/ Simulink.
\end{abstract}

Keywords: Electric Arc Furnaces, Power Quality, Voltage Flicker, MATLAB/Simulink, TCR-TSC Compensation

\section{Introduction}

The use of electric arc furnaces (EAFs) for steel making has grown dramatically in the last decade. Of the steel made today $36 \%$ is produced by the electric arc furnace route and this share will increase to $50 \%$ by 2030 . The electric arc furnaces are used for melting and refining metals, mainly iron in the steel production. AC and DC arc furnaces represent one of the most intensive disturbing loads in the sub-transmission or transmission electric power systems; they are characterized by rapid changes in absorbed powers that occur especially in the initial stage of melting, during which the critical condition of a broken arc may become a short circuit or an open circuit. In the particular case of the DC arc furnaces, the presence of the $\mathrm{AC} / \mathrm{DC}$ static converters and the random motion of the electric arc, whose nonlinear and time-varying nature is well known, are responsible for dangerous perturbations such as waveform distortions and voltage fluctuations [2].

Nowadays, arc furnaces are designed for very large power input ratings and due to the nature of both, the electrical arc and the melt down process, these devices can cause large power quality problems on the electrical network, mainly harmonics, inter-harmonics, flicker and voltage imbalances. The EAFs are among the largest electrical loads in power systems. Regarding the fast and heavy deviations of electric power in these loads, the bus voltage of these furnaces is unbalanced and has large oscillations. Moreover, the EAFs cause deteriorating of the power quality, making voltage flicker, unbalancing in voltage and current, and occurring odd and even harmonics in power systems. In order to study in this field and improve the above mentioned factors, exact and complete design of the power system with arc furnaces should be performed [1].

\section{Power Quality and Electrical Arc Furnaces}

Power quality can be interpreted by the existence of two components:

- Voltage quality. It expresses the voltage deviation from the ideal one and can be interpreted as the product 
quality delivered by the utilities.

- Current quality. It expresses the current deviation from the ideal one and can be interpreted as the product quality received by the customers.

The main Power quality disturbances are:

- Harmonics

- Under-voltages or Over-voltages

- Flicker

- Transients

- Voltage sags

- Interruptions.

An electric arc furnace (EAF) transfers electrical energy to thermal energy in the form of an electric arc to melt the raw materials held by the furnace [3]. Typical steelmaking cycles are:

- Arc ignition period (start of power supply)

- Boring period

- Molten metal formation period

- Main melting period

- Meltdown period

- Meltdown heating period respectively.

\section{Model of Power System with AC Electric Arc Furnace}

The electric diagram of a source supplying an EAF is illustrated in Figure 1.

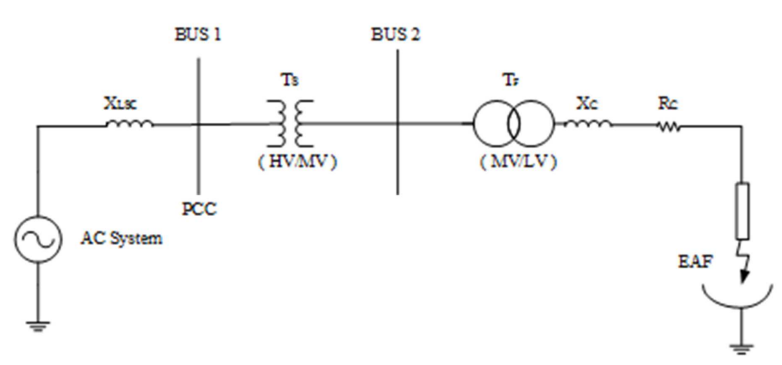

Figure 1. Diagram of an EAF connected to the rest of power system.

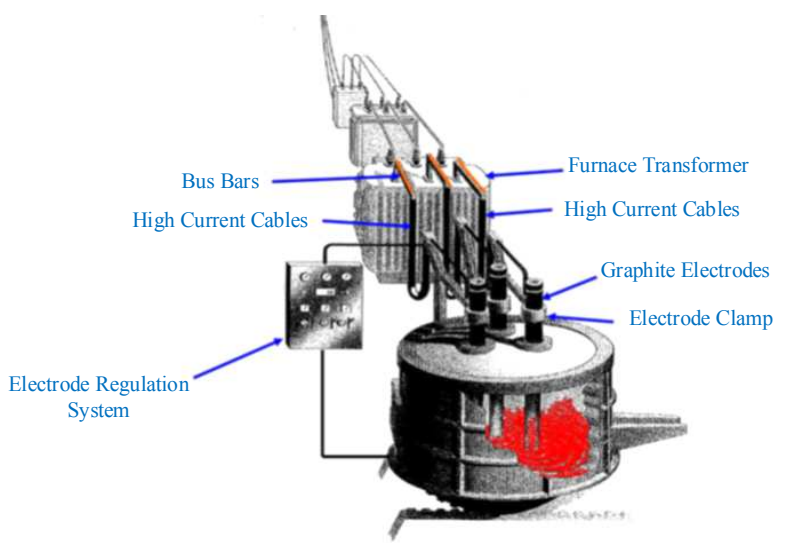

Figure 2. Electrical Power Supply Network for EAF in No(1) Iron and Steel Mill.

In this figure, bus 1 is the point of common coupling (PCC) which is the supplying bus of the EAF transformer. In order to change the input active power of the EAF, transformer $T_{F}$, $(\mathrm{MV} / \mathrm{LV})$ is used. This transformer is equipped with a tap changer located at the secondary winding to have the ability of changing the voltage of the furnace. The arc furnace is also connected to the PCC through the transformer $\mathrm{T}_{\mathrm{S}}$, (HV/MV). $\mathrm{X}_{\mathrm{C}}$ and $\mathrm{R}_{\mathrm{C}}$ are the reactance and resistance of the connecting cable line to the furnace electrodes, respectively. Also, $\mathrm{X}_{\mathrm{Lsc}}$ is the short circuit reactance at bus PCC.

In this work, the steel mill No.1, (Pyin Oo Lwin, Mandalay, Myanmar) is composed of the various departments, namely, Electric Arc Furnace (EAF), Ladle Refining Furnace (LRF), Continuous Casting Machine (CCM), Water Treatment Plant (WTP), Fumes Treatment Plant (FTP), Air Separation Plant (ASP), Oxygen Plant, Wire Production Plant, Precipitated Calcium Carbonate (PCC) CaCO3, Lime, Air Compressor, Shredder and Bolt Nut. Among these departments, EAF is studied as research area.

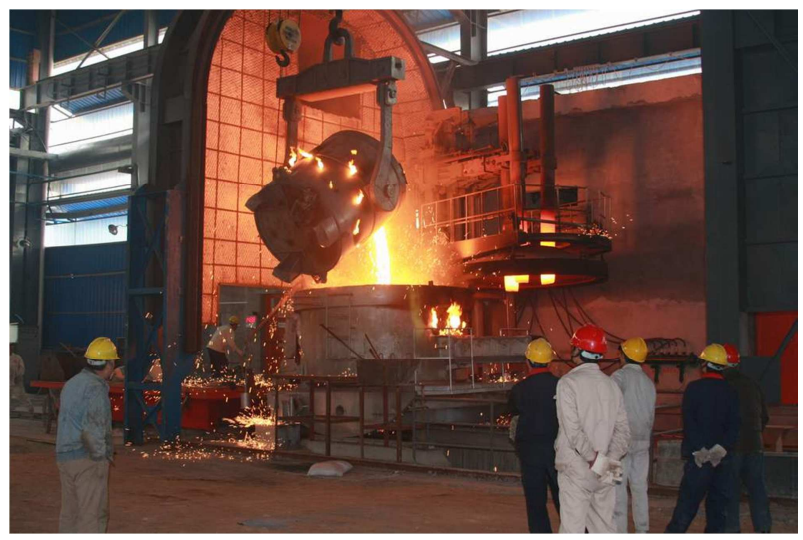

Figure 3. Practical Site of No(1) Iron and Steel Mill.

\section{Design of TCR-TSC for Electric Arc Furnace}

In order to compensate reactive power and voltage flicker improvement in power system including the EAF and on the basis of Figure 1, in this section, an optimal design of TCR compensator along with a parallel capacitor will be presented. The one-line diagram of this structure is illustrated in Figure 4.

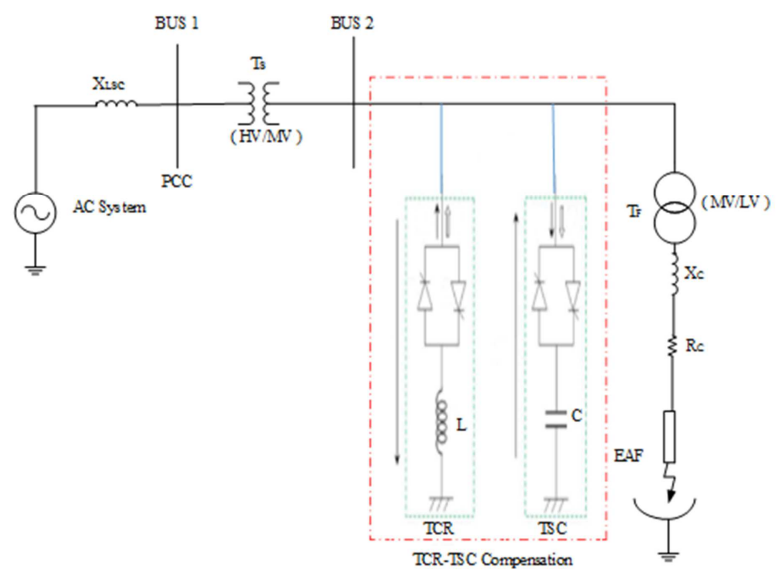

Figure 4. Configuration of a TCR-TSC Connected to an EAF. 
As it can be seen in Figure 4, the effective inductance of the TCR compensator can be varied by changing the firing angle of the thyristors. If the thyristors are fired exactly at the voltage peak of the supply, then they will conduct perfectly. The TCR current is essentially reactive with almost 90 degrees lag phase.

The operation of EAF Plant, steelmaking cycle is represented in Table 1.

Table 1. Typical Steelmaking Cycle of Proposed System.

\begin{tabular}{|c|c|c|c|c|}
\hline $\begin{array}{l}\text { Stage of } \\
\text { Melting }\end{array}$ & $\begin{array}{l}\text { Time } \\
\text { (min) }\end{array}$ & $\begin{array}{l}\text { Voltage } \\
(\mathrm{kV})\end{array}$ & $\begin{array}{l}\text { Reactive Power } \\
\text { (MVAR) }\end{array}$ & $\begin{array}{l}\text { Real Power } \\
\text { (MW) }\end{array}$ \\
\hline \multirow{2}{*}{ Bucket 1} & 0 & 11 & 0 & 0 \\
\hline & 2.91 & 11 & 0 & 0 \\
\hline \multirow{2}{*}{ Initial Melting } & 2.92 & 9.84 & 16.49 & 21.99 \\
\hline & 3.68 & 9.84 & 16.49 & 21.99 \\
\hline \multirow{2}{*}{ Bore Down } & 3.69 & 10.87 & 13.81 & 18.41 \\
\hline & 4.32 & 10.87 & 13.81 & 18.41 \\
\hline \multirow{2}{*}{ Melting } & 4.33 & 9.71 & 22.635 & 30.18 \\
\hline & 8.51 & 9.71 & 22.635 & 30.18 \\
\hline \multirow{2}{*}{ Melting } & 8.52 & 8.81 & 20.87 & 27.83 \\
\hline & 9.09 & 8.81 & 20.87 & 27.83 \\
\hline \multirow{2}{*}{ Melting } & 9.10 & 9.88 & 18.795 & 25.06 \\
\hline & 10.52 & 9.88 & 18.795 & 25.06 \\
\hline \multirow{2}{*}{ Melting } & 10.53 & 9.17 & 25.29 & 33.72 \\
\hline & 16.27 & 9.17 & 25.29 & 33.72 \\
\hline \multirow{2}{*}{ End Melting } & 16.28 & 10.10 & 24.06 & 32.09 \\
\hline & 17.93 & 10.10 & 24.06 & 32.09 \\
\hline \multirow{2}{*}{ Finish Bucket 1} & 17.94 & 10.97 & 0 & 0 \\
\hline & 19.22 & 10.97 & 0 & 0 \\
\hline Initial & 19.23 & 10.68 & 15.42 & 20.57 \\
\hline Melting/Boring & 19.94 & 10.68 & 15.42 & 20.57 \\
\hline \multirow{2}{*}{ Melting } & 19.95 & 9.73 & 25.18 & 33.57 \\
\hline & 20.53 & 9.73 & 25.18 & 33.57 \\
\hline \multirow{2}{*}{ Melting } & 20.54 & 9.00 & 21.27 & 28.36 \\
\hline & 24.03 & 9.00 & 21.27 & 28.36 \\
\hline \multirow{2}{*}{ Melting } & 24.04 & 8.56 & 24.74 & 32.99 \\
\hline & 29.69 & 8.56 & 24.74 & 32.99 \\
\hline \multirow{2}{*}{ Finish Bucket 2} & 29.70 & 10.97 & 0 & 0 \\
\hline & 31.89 & 10.97 & 0 & 0 \\
\hline Initial & 31.90 & 7.81 & 16.03 & 21.38 \\
\hline Melting/Boring & 32.51 & 7.81 & 16.03 & 21.38 \\
\hline \multirow{2}{*}{ Bore Down } & 32.52 & 10.17 & 24.07 & 32.09 \\
\hline & 33.40 & 10.17 & 24.07 & 32.09 \\
\hline \multirow{2}{*}{ Melting } & 33.41 & 8.87 & 22.38 & 29.84 \\
\hline & 36.13 & 8.87 & 22.38 & 29.84 \\
\hline \multirow{2}{*}{ Melting } & 36.14 & 8.99 & 25.39 & 33.86 \\
\hline & 41.97 & 8.99 & 25.39 & 33.86 \\
\hline \multirow{2}{*}{ Melting } & 41.98 & 10.99 & 0 & 0 \\
\hline & 42.23 & 10.99 & 0 & 0 \\
\hline \multirow{2}{*}{ Melting } & 42.24 & 10.26 & 24.50 & 32.67 \\
\hline & 48.80 & 10.26 & 24.50 & 32.67 \\
\hline \multirow{2}{*}{ End Melting } & 48.81 & 9.96 & 24.315 & 32.42 \\
\hline & 50.64 & 9.96 & 24.315 & 32.42 \\
\hline End Melting/ & 50.65 & 9.81 & 23.46 & 31.28 \\
\hline Superheating & 51.84 & 9.81 & 23.46 & 31.28 \\
\hline \multirow{3}{*}{ Finish Bucket 3} & 51.85 & 10.98 & 0 & 0 \\
\hline & 53.56 & 10.98 & 0 & 0 \\
\hline & 53.57 & 11 & 0 & 0 \\
\hline \multirow[t]{2}{*}{ End Melting } & 57.17 & 11 & 0 & 0 \\
\hline & 57.18 & 11 & 0 & 0 \\
\hline
\end{tabular}

The compensated values for the capacitance and the compensated TCR inductance are calculated based on this setting.

$$
\mathrm{X}_{\mathrm{SVC}}=\frac{\mathrm{V}_{\text {bus }}^{2}}{\mathrm{Q}_{\mathrm{SVC}}}
$$

$$
\therefore \mathrm{X}_{\mathrm{SVC}}=4.7845 \Omega
$$

$$
\begin{gathered}
X_{\mathrm{SVC}}=\frac{\mathrm{X}_{\mathrm{TSC}} \mathrm{X}_{\mathrm{TCR}}}{\mathrm{X}_{\mathrm{TSC}}+\mathrm{X}_{\mathrm{TCR}}} \\
\mathrm{X}_{\mathrm{TSC}}=2 \mathrm{X}_{\mathrm{TCR}}
\end{gathered}
$$

$$
\begin{aligned}
& \mathrm{X}_{\mathrm{SVC}}=0.6667 \mathrm{X}_{\mathrm{TCR}} \\
& \therefore \mathrm{X}_{\mathrm{TCR}}=7.1764 \Omega
\end{aligned}
$$

\begin{tabular}{|c|c|c|c|}
\hline No & Load (EAF) & $\begin{array}{l}\text { Compensating } \\
\text { Inductance } \mathrm{mH}\end{array}$ & $\begin{array}{l}\text { Compensating } \\
\text { Capacitance } \mu \mathrm{F}\end{array}$ \\
\hline 1 & 2.0 ton & 23.759 & 213.224 \\
\hline 2 & 3.0 ton & 23.579 & 214.848 \\
\hline 3 & 4.0 ton & 23.351 & 216.954 \\
\hline 4 & 5.0 ton & 22.843 & 221.780 \\
\hline 5 & 7.0 ton & 22.753 & 222.650 \\
\hline 6 & 0.5 ton & 41.832 & 121.104 \\
\hline 7 & 1.0 ton & 37.464 & 135.223 \\
\hline 8 & 1.5 ton & 36.039 & 140.573 \\
\hline 9 & 1.8 ton & 35.030 & 144.686 \\
\hline 10 & 1.9 ton & 30.796 & 164.500 \\
\hline
\end{tabular}

$$
\begin{aligned}
& \mathrm{X}_{\mathrm{TCR}}=2 \pi f \mathrm{~L} \\
& \mathrm{X}_{\mathrm{TSC}}=\frac{1}{2 \pi f \mathrm{C}}
\end{aligned}
$$

Table 2. Compensated Values of Inductor and Capacitor.

The maximum reactive capacity of the TCR-TSC is set at $\mathrm{Q}_{\mathrm{sVC}}=25.39 \mathrm{MVAR}$

From Equation 4 and Equation 5, considering a fundamental frequency is of $50 \mathrm{~Hz}$. The capacitance and inductances are $\mathrm{C}=222.65 \mu \mathrm{F}$ and $\mathrm{L}=22.7532 \mathrm{mH}$.

According to the inductive and capacitive reactance, each SVC has its own firing angle reactive power characteristic, $\mathrm{Q}_{\mathrm{SVC}}(\alpha)$ which is a function of the inductive and capacitive reactance.

It is necessary to obtain the effective reactance $X_{\mathrm{SVC}}$ as a function of the firing angle $\alpha$, using the fundamental frequency TCR equivalent reactance $\mathrm{X}_{\mathrm{TCR}}$.

$$
\begin{gathered}
\mathrm{X}_{\mathrm{TCR}}=\frac{\pi \mathrm{X}_{\mathrm{L}}}{\sigma-\sin \sigma} \\
\sigma=2(\pi-\alpha)
\end{gathered}
$$

Where $X_{L}$ is the reactance of the linear inductor and $\sigma$ and $\alpha$ are the thyristors' conduction angle and firing angle repectively. 
At $\alpha=90^{\circ}$ the TCR conducts fully and its equivalent reactance $\mathrm{X}_{\mathrm{TCR}}$ becomes $\mathrm{X}_{\mathrm{L}}$.

At $\alpha=180^{\circ}$ the TCR is blocked and its equivalent reactance becomes extremely large. It is also expressed in Table 3.

Table 3. Variation of Value of $\mathrm{B}_{\mathrm{L}}$ with Firing Angle.

\begin{tabular}{llll}
\hline $\begin{array}{l}\text { Firing Angle } \\
\alpha \text { (Degree) }\end{array}$ & $\begin{array}{l}\text { Conduction Angle } \\
\sigma \text { (Degree) }\end{array}$ & $\begin{array}{l}\text { Susceptance } \\
\mathrm{B}_{\mathrm{L}}(\alpha)\end{array}$ & $\begin{array}{l}\text { Perunit of } \\
\mathrm{B}_{\mathrm{L}}(\alpha)\end{array}$ \\
\hline $90^{\circ}$ & $180^{\circ}$ & 0.028 & 1 \\
$100^{\circ}$ & $160^{\circ}$ & 0.022 & 0.8 \\
$110^{\circ}$ & $140^{\circ}$ & 0.016 & 0.6 \\
$120^{\circ}$ & $120^{\circ}$ & 0.011 & 0.4 \\
$130^{\circ}$ & $100^{\circ}$ & $6.7 \times 10^{-3}$ & 0.2 \\
$140^{\circ}$ & $80^{\circ}$ & $3.63 \times 10^{-3}$ & 0.1 \\
$150^{\circ}$ & $60^{\circ}$ & $1.59 \times 10^{-3}$ & 0.06 \\
$160^{\circ}$ & $40^{\circ}$ & $4.88 \times 10^{-3}$ & 0.02 \\
$170^{\circ}$ & $20^{\circ}$ & $6.21 \times 10^{-3}$ & 0.002 \\
$180^{\circ}$ & 0 & 0 & 0 \\
\hline
\end{tabular}

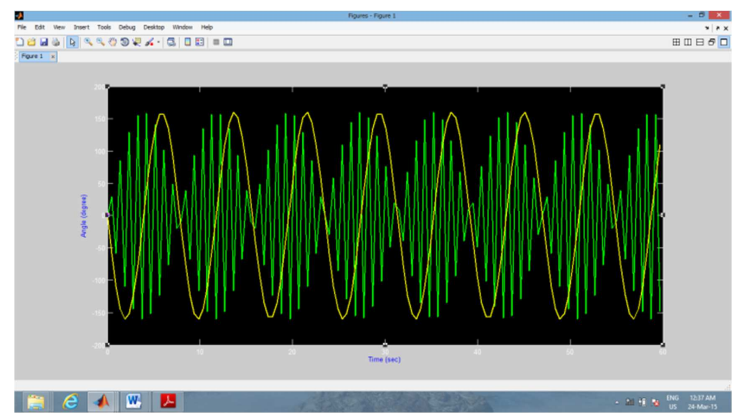

Figure 5. Sinusoidal Waveform of Conduction Angle and Firing Angle.

The total effective reactance of the SVC, including the TCR and capacitive reactance, is determined by the parallel combination of both components and which as a function of the conduction angle $\sigma$ becomes

$$
\mathrm{X}_{\mathrm{L}}=\frac{\mathrm{X}_{\mathrm{TCR}}(\sigma-\sin \sigma)}{\pi}
$$

And finally as a function of the firing angle $\alpha$ becomes

$$
\mathrm{X}_{\mathrm{SVC}}=\frac{\mathrm{X}_{\mathrm{TSC}} \pi \mathrm{X}_{\mathrm{L}}}{\mathrm{X}_{\mathrm{TSC}}[2 \pi-2 \alpha+\sin 2 \alpha]+\pi \mathrm{X}_{\mathrm{L}}}
$$

As expected, the effective reactance of the SVC is a function of the firing angle $\alpha$. Equation 9 may be used to determine the firing angle $\alpha$, using the fundamental relationship.

$$
\mathrm{Q}_{\mathrm{SVC}}=\mathrm{V}_{\text {bus }}^{2}\left[\frac{\mathrm{X}_{\mathrm{TSC}}[2 \pi-2 \alpha+\sin 2 \alpha]+\pi \mathrm{X}_{\mathrm{L}}}{\mathrm{X}_{\mathrm{TSC}} \pi \mathrm{X}_{\mathrm{L}}}\right]
$$

At initial melting conduction, the reactive power of the load is set $16.49 \mathrm{MVAR}$ and bus voltage is $9.84 \mathrm{kV}$ respectively. The calculation of firing angle value is $156^{\circ}$ and the next stages are also calculated as before.

By using the iteration method, the next step to go on calculate until the voltage level is stable.

$$
\mathrm{V}_{\text {bus }}=\mathrm{V}_{\text {ref }}-\mathrm{V}_{\text {drop }}
$$

By iteratively, the voltage level is stable with $10.2 \mathrm{kV}$ at the step (18). In this way, another condition will also calculate till stable.

The new total melting time has been reduced from 51.85 min down to $47.16 \mathrm{~min}$ which is $9.05 \%$ reduction. The power on time has been reduced from $48.36 \mathrm{~min}$ down to $43.68 \mathrm{~min}$ which is $9.7 \%$ reduction.

The new melting times have been calculated assuming that furnace is able to transfer increased power into melting process by the similar efficiency than in the system without TCR-TSC compensator. The comparison of times without and with TCR-TSC is presented in Table 4 and Table 5.

Table 4. Total Melting Times

\begin{tabular}{ll}
\hline Time (min) Without TCR-TSC & Time (min) With TCR-TSC \\
\hline 51.85 & 47.16 \\
Reduction in time & $9.05 \%$ \\
\hline
\end{tabular}

Table 5. Power On Times.

\begin{tabular}{lll}
\hline $\begin{array}{l}\text { Time (min) Without } \\
\text { TCR-TSC }\end{array}$ & $\begin{array}{l}\text { Time (min) With } \\
\text { TCR-TSC }\end{array}$ \\
\hline Bucket 1 & 17.94 & 15.94 \\
Bucket 2 & 10.47 & 9.05 \\
Bucket 3 & 19.95 & 18.69 \\
Total & 48.36 & 43.68 \\
Reduction in time & $9.7 \%$ \\
\hline
\end{tabular}

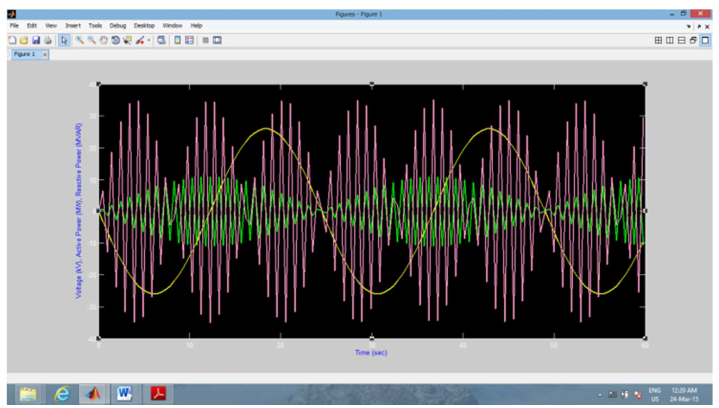

Figure 6. Sinusoidal Waveform of Voltage and Power for EAF Load System without TCR-TSC

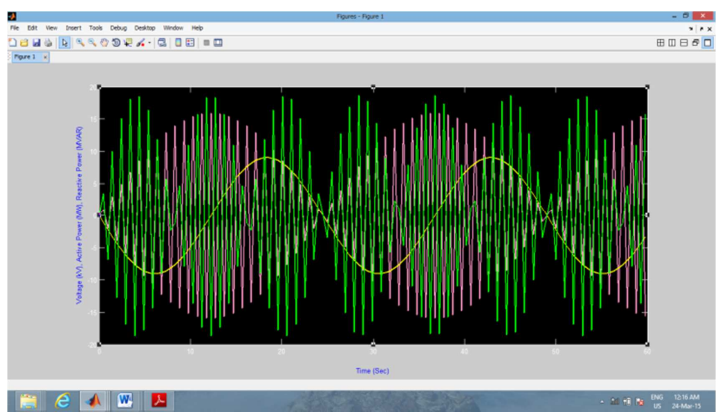

Figure 7. Sinusoidal Waveform of Voltage and Power for EAF Load System with TCR-TSC. 


\section{Simulation Result for Voltage and Current}

The power quality means voltage quality for this work and to enhance the power quality i.e., to keep the voltage stability is the aim. Voltage stability problems usually encounter in heavily loaded systems.

EAF is operating to melt down the scrap in a moment. During melting cases, generally, the system voltage decreased from the constant level. If the running condition stopped, the voltage will suddenly rise.

The simulation diagram and simulation result without and TCR-TSC are described in the following Figure 8, Figure 9 and Figure 10.

The inserted values of inductance and resistance of EAF model are $0.148 \mathrm{mH}$ and $0.053 \Omega$. Figure 8 shows Simulink block diagram of EAF without TCR-TSC. The result without TCR-TSC was found in Figure 9 for voltage and in Figure 10 for current. The TCR-TSC compensator operates on single phase basis and thus it is balancing the voltage.

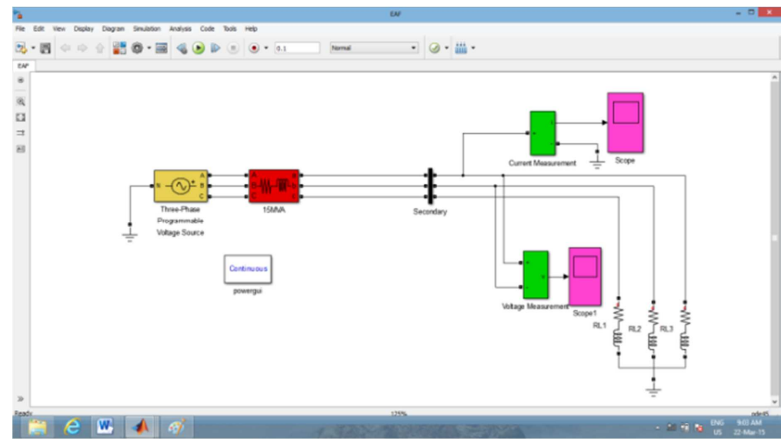

Figure 8. Simulink Block Diagram of EAF without TCR-TSC.

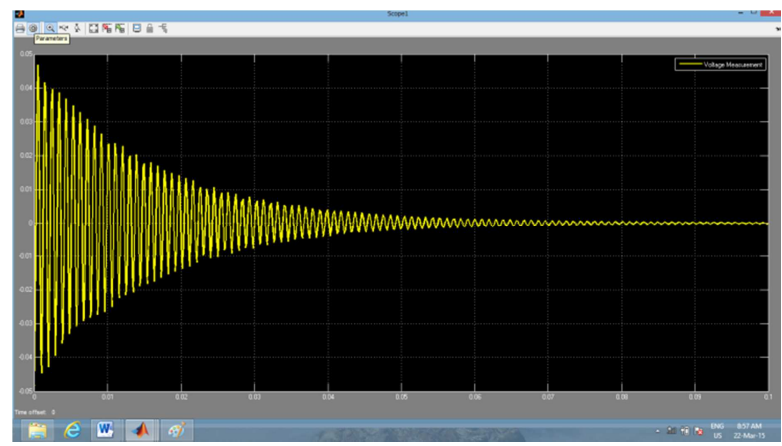

Figure 9. Simulation Result of Voltage without TCR-TSC.

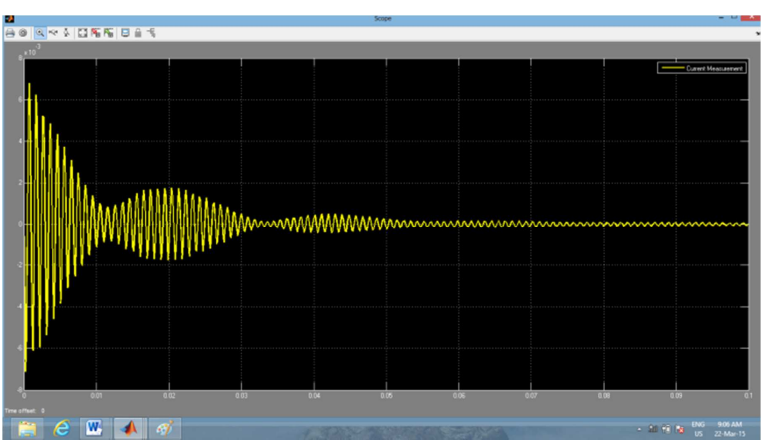

Figure 10. Simulation Result of Current without TCR-TSC.
To obtain the desire results, a TCR-TSC is added to the EAF. The Simulink block diagram of EAF with TCR-TSC is shown in Figure 11. The system voltage of bore down process with 25.29 MVAR, 33.72 MW and 9.17 kV is stable as can be seen in Figure 12. The current flow is expressed in Figure 13.

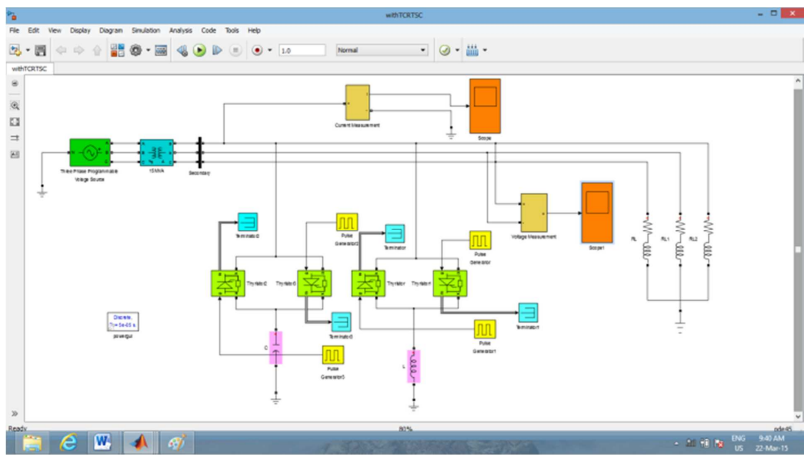

Figure 11. Simulink Block Diagram of EAF with TCR-TSC.

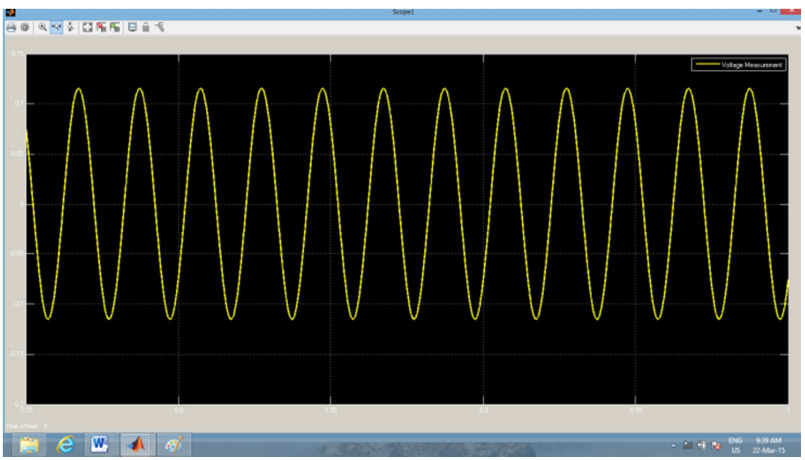

Figure 12. Simulation Result of Voltage with TCR-TSC.

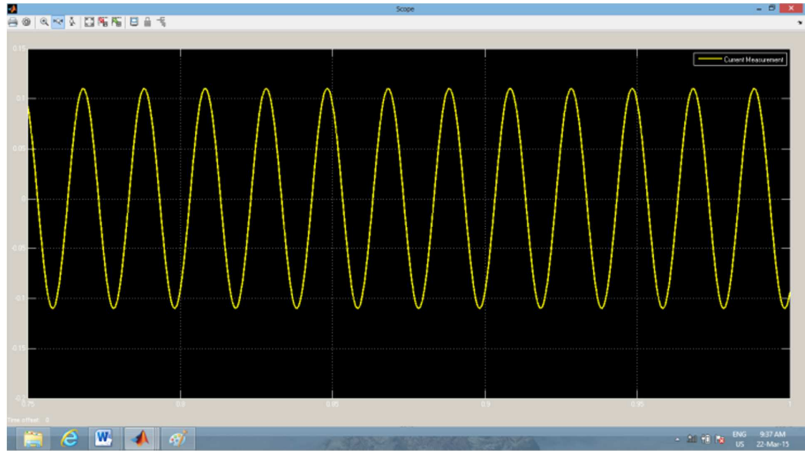

Figure 13. Simulation Result of Current with TCR-TSC.

The TCR-TSC will stabilize the voltage. This is advantageous not only for the furnace itself but also for the control and protection system of the steel making plant because modern electronics and process instruments are very sensitive to voltage fluctuations. The TCR-TSC can reduce the flicker down to the value requested by the power utility.

\section{Conclusion}

This paper provides a detailed description of a modern, TCR-TSC type Static Var Compensator installed in steel making plant. The Electric Arc Furnace (EAF) for steel production is analyzed. The reactive power compensation 
requirements are quantitatively analyzed. The TCR-TSC is a controller for voltage regulation and for maintaining constant voltage at a bus. This can result saving in operational costs, reduced line losses, reduction operating time, rise the steel tons, etc.

\section{Acknowledgements}

The author would like to express grateful thanks to her supervisor Dr. Soe Win Naing, Associate Professor, Department of Electrical Power Engineering, Mandalay Technological University, for his help, guidance and advice. The author wishes to thank to all of her teachers from Mandalay Technological University. The author's special thanks are sent to her father, mother and sister for their support and encouragement.

\section{References}

[1] S. Y. Lee, C. J .Wu and W. N. Change, A compact control algorithm for compensator, Electric Power System Research, 58, 2001, pp. 63-70.

[2] G. E1-Saady, Adaptive static VAR controller for simultaneous elimination of voltage flicker and phase current imbalances due

\section{Biography}

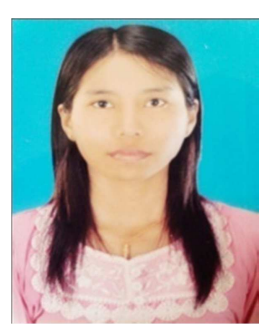

\section{Ms. Thet Mon Aye}

She received the BE degee in Electrical Power Engineeringfrom Technological University (Pakokku), Myanmar in 2007. Since June 2009, she became a Demonstrator at Technological University (Kalay) Under Ministry of Science and Technology, Myanmar. And then, she obtained ME degree in Electrical Power Engineering from Mandalay Technological University, Myanmar, in 2011 by serving her duty. Now, her mother unit is Technological University (Myitkyinar) and she is attending Ph.D degree in Electrical Power Engineering at Mandalay Technological University, Mandalay, Myanmar to arc furnace loads, Electric Power Systems Research, 58, 2001, pp.133-140.

[3] T. J. E. Miller, Reactive Power Compensation and the Electric Arc Furnace, 2002.

[4] Robertas Staniulis., Reactive Power Valuation, Department of Industrial Electrical Engineering and Automation Lund University, Lund, 2001.

[5] Md M. Biswas, Kamol K. Das, Voltage level improving by using static VAR compensator, Global Journal of Research in Engineering Vol.11, Issue 5, Version 1.0, 2011.

[6] Wangha L., Taewon K., Control of the Thyristor-Controlled Reactor for reactive power compensation and load balancing, IEEE Conference on Industrial Electronics and Applications (ICIEA), 2007, pp. 201-206.

[7] Hingorani, N.G., Flexible AC Transmission, IEEE Spectrum, 1993, pp.40-44.

[8] M. N. Murthy, Director, Reactive Power Fundamentals, PSTI, Bangalore, January 2003.

[9] Golkar M.A., Meschi S., MATLAB modeling of arc furnace for flicker study, IEEE Conference on Industrial Technology (ICIT), 2008, p.1-6.

[10] Hingornai, N.G. and Gyugyi, L, Understanding FACTS, IEEE Press, Newyork, 1999. 